\title{
Corrigendum: The Harvard Beat Assessment Test (H-BAT): a battery for assessing beat perception and production and their dissociation
}

\section{Shinya Fujii' and Gottfried Schlaug ${ }^{2 *}$}

${ }^{1}$ Heart and Stroke Foundation Canadian Partnership for Stroke Recovery, Sunnybrook Research Institute, Toronto, ON, Canada

${ }^{2}$ Department of Neurology, Beth Israel Deaconess Medical Center and Harvard Medical School, Boston, MA, USA

${ }^{*}$ Correspondence: gschlaug@bidmc.harvard.edu

Edited and reviewed by:

Shinichi Furuya, Sophia University, Japan

Keywords: rhythm, beat, meter, synchronization, beat-deafness, battery, dissociation

\section{A corrigendum on}

The Harvard Beat Assessment Test (H-BAT): a battery for assessing beat perception and production and their dissociation

by Fujii S and Schlaug G. (2013) Front. Hum. Neurosci. 7:771. doi: 10.3389/fnhum. 2013.00771

One of the references in this article contained a misspelling of an author name ("Shuit"), which we hereby rectify to "Schuit."

\section{REFERENCE}

Grahn, J. A., and Schuit, D. (2012). Individual differences in rhythmic ability: behavioral and neuroimaging investigations. Psychomusicology 22, 105-121. doi: 10.1037/a0 031188

Conflict of Interest Statement: The authors declare that the research was conducted in the absence of any commercial or financial relationships that could be construed as a potential conflict of interest.

Received: 17 September 2014; accepted: 08 October 2014; published online: 04 November 2014.
Citation: Fujii S and Schlaug G (2014) Corrigendum: The Harvard Beat Assessment Test (H-BAT): a battery for assessing beat perception and production and their dissociation. Front. Hum. Neurosci. 8:870. doi: 10.3389/ fnhum.2014.00870

This article was submitted to the journal Frontiers in Human Neuroscience.

Copyright $\odot 2014$ Fujii and Schlaug. This is an openaccess article distributed under the terms of the Creative Commons Attribution License (CC BY). The use, distribution or reproduction in other forums is permitted, provided the original author(s) or licensor are credited and that the original publication in this journal is cited, in accordance with accepted academic practice. No use, distribution or reproduction is permitted which does not comply with these terms. 